\title{
Cleaning-In-Place (CIP) System in Dairy Plant- Review
}

\author{
Amitha Thomas ${ }^{1}$ and C. T. Sathian ${ }^{2}$ \\ Dept. of Dairy Science \\ College of Veterinary and animal Sciences, Mannuthy \\ Kerala Veterinary and Animal Sciences University, India
}

\begin{abstract}
Cleaning In Place (CIP) system of cleaning the interior surface of pipelines, vessels, filters, process equipment and associated things without dismantling. Depending on the processing practice and load of soiling on the process equipment, the cleaning solutions may be used for single cycle or recycled and reused for multi use. Cleaning-In-Place systems shortens the required time for cleaning, besides using detergents and disinfectants at higher concentrations and temperatures, as well as the recovery of the cleaning solutions. The automation of these systems also allows for safe and reproducible results and economic optimization of the process. In CIP system, cleaning solutions used include various types of detergents, sanitizers or disinfectants. To achieve the most effective CIP results, it is necessary to design the production process and the CIP components and circuits simultaneously, giving equal consideration to production and cleaning requirements

Key words: Cleaning In Place (CIP), Dairy plant, Cleaning efficiency
\end{abstract}

\section{Introduction}

Cleaning In Place (CIP) system of cleaning the interior surface of pipelines, vessels, filters, process equipment and associated things without dismantling. Industries that require high level of hygiene rely on CIP and they include dairy, beverage, brewing, pharmaceuticals, processed foods and cosmetics. The efficiency of cleaning and sanitation of milk contact surfaces are widely influenced by many factors like the character of contamination, micro topography of surfaces, straightness of passage ways, compatibility of surface agents, application methods, speed of application and related speed of penetration in to biofilm structure (Jones et al., 1986). Depending on the processing practice and load of soiling on the process equipment, the cleaning solutions may be used for single cycle or recycled and reused for multi use. In multiple use, cleaning solutions are drained after a few to several hundred cleaning cycles (Merin et al., 2002). In the dairy industry, reuse and multi use CIP systems operate by circulating chemicals and water without taking the equipment apart. Whatever the CIP mode of operation, cleaning solutions are periodically drained when they are considered to be too polluted (Genevihe et al., 2002). The effectiveness of cleaning is preconditioned by factors like chemical agent, mechanical power, temperature, and time of the procedure, which together form the Sinner circle (Wirtanen and Salo, 2003). Cleaning in place sanitation in the dairy industry and on farms has some specific features. It is necessary to remove both the remaining organic contamination, milk and water plaque. The sanitation regime of CIP is set up so as to guarantee the elimination of organic and inorganic contaminations, disinfection of the cleaned surface from live cells of microorganisms to 99.9 per cent and elimination of the residues of the sanitation agents (Vlkovai et al., 2008).

Cleaning-In-Place (CIP) involves the jetting or spraying of surfaces or circulation of cleaning solutions through the plant under conditions of increased turbulence and flow velocity. The processed food industry including beverage industry have shown a major shift towards CIP over the past $10-15$ years. It has seen increased demands from customers in terms of CIP verification and validation to provide improvements in plant hygiene, finished product quality, and related shelf-life and microbiological considerations (Tamime, 2008). It is important that cleaning procedures have to ensure the hygiene in food processing lines by the complete removal of bacteria from surfaces (Gentil et al., 2010). Cleaning-In-Place systems shortens the required time for cleaning, besides using detergents and disinfectants at higher concentrations and temperatures, as well as the recovery of the cleaning solutions. The automation of these systems also allows for safe and reproducible results and economic optimization of the process ( Gracia and Diaz, 2011).

\section{Types of cleaning in food industry}

Walker et al. (2003) carried out CIP cleaning of a pipeline milking system using electrolyzed oxidizing water. The pipeline system was washed with an alkaline electrolyzed oxidized water treatment followed by an acidic electrolyzed oxidized water treatment. Levels of cleaning that might be considered as physically clean, chemically clean and microbiologically clean. Physically clean addresses the aesthetic aspect. The surface appears clean, but chemical residues, often deliberately left to achieve a particular desired effect, may have been allowed to remain and disinfection of the surface has not been considered. The chemically clean surface is 
rendered totally free from any trace of chemical residues and microbiologically clean addresses the degree of microbiological contamination (Tamime, 2008).

\section{Cleaning solutions}

In CIP system, cleaning solutions used include various types of detergents, sanitizers or disinfectants (Tamime, 2008).

\section{Detergents}

The detergents used in CIP system may be alkali or acid detergents. The commonly used alkali detergents are Sodium Hydroxide, Potassium Hydroxide, sodium Carbonate etc and the acid detergents include Hydrochloric Acid, Nitric Acid, Phosphoric Acid, Citric acid etc.

Alkali detergents

Alkaline cleaners are those that have a pH higher than 7. They are commonly used in the dairy industry because they saponify fat and convert the fat to soap and can be removed with water. These are usually consist of sodium hydroxide (caustic soda) potassium hydroxide (caustic potash), sodium carbonate (soda ash), and sodium silicates. Tri sodium phosphate (TSP) is also placed into the alkali group because of its reaction with water to yield hydroxide ions ( Dairy Practice Council, 1993). Milk stones in pipelines are removed by hot alkali (caustic soda) assisted by wetting agents that break up the protein into water soluble units. Typically $0.5-2$ per cent caustic soda has been used at temperatures of up to $85^{\circ} \mathrm{C}$. For highly fouled surfaces, up to 4 per cent caustic soda can be applied (Mosteller and Bishop, 1993). The best cleaning effect for surfaces with the burned milk soil was achieved with a two phase cleaning procedure using chelator based sodium hydroxide ( Wirtanen and Salo, 2003). Caustic soda is a very strong alkali, and is a commonly used material in formulating detergents for use in CIP and other mechanical means of cleaning because of its relatively low cost. It exhibits excellent removal of proteinaceous soils and fatty oils by saponification (Tamime, 2008). The most common and aggressive alkali cleaner is sodium hydroxide $(\mathrm{NaOH})$. It is typically used in concentrations between 0.15 and 1.0 per cent at temperatures in the range of $70-80^{\circ} \mathrm{C}$ for 10 to $30 \mathrm{~min}$. However, for heavily soiled surfaces, especially those containing burnt on protein, such as found in plate-type and tubular heat exchangers, concentrations up to 5 per cent are used (Bremer and Seale, 2010).

Acid detergents

Acid circulation in CIP procedures for pasteurization is included to remove encrusted protein and salts from the surfaces of heat treatment equipment and the flow rate must be greater than $1.5 \mathrm{~m} / \mathrm{sec}$ to achieve the mechanical force necessary to prevent biofilm buildup (Wirtanen and Salo, 2003). The most common acids found in dairy cleaning are the inorganic acids, such as phosphoric acid and nitric acid, and the organic acids, such as citric acid. Other mineral acids that may be used from time to time are hydrochloric acid and sulphuric acid. Organic acids like hydroxyacetic acid and gluconic acid are also used (Tamime, 2008). Following an alkaline wash, an acid detergent wash is applied in order to remove any traces of alkaline product from equipment surfaces. It enhances draining and drying of pipelines and provide bacteriostatic conditions that delay the growth of organisms that may be found in the water supply. It will also help in removing mineral deposits such as hard water stone, beer stone, calcium oxalate, or milk stone. The most common acid detergent is nitric acid, which is generally used at a concentration of $0.5-1.0$ per cent under either ambient or heated conditions $\left(55-80^{\circ} \mathrm{C}\right)$ for 5 to 20 minutes (Bremer and Seale, 2010).

\section{Sanitizers}

Disinfectants used in the food processing industry include oxidizing agents such as hypochlorite, hydrogen peroxide, ozone and per acetic acid. Denaturing agents like alcohol based products and non oxidizing and surface tension diminishing agents and enzyme based products are also used(Troller, 1993). Sanitizers based on peroxygen can eliminate spores but they are corrosive at high temperature and concentration (Russel and Chopra, 1996). Basic requirements for sanitation at the processing facilities are effectiveness, economy, and safety. An effective and safe sanitation regime reaches economic effectiveness if the sanitation agent can be easily washed out, low demand on energy and work and the least damage to the environment and disinfected surfaces (Salo et al., 2001). Wirtanen and Salo (2003) suggested that the sanitizers must be used at either high concentration or at high temperature to be able to eliminate spores, but it is apparently not suitable for practical disinfection due to corrosion and toxicity. The process includes both cleaning off deposits of organic and inorganic matters mixed with microorganisms and the process of devitalisation of microorganisms, which may be the primary cause of the formation of the plaques (Vlkovai et al., 2008). Sodium hypochlorite based sanitizers are widely used as they have many features which make them desirable for CIP applications. They are active against a wide range of microorganisms, including gram-positive and gram-negative bacteria, bacterial spores, and viruses (Bremer and Seale, 2010). 


\section{Cleaning efficiency}

The bore water supplies are the major source of microbial contamination to the flush water. The commonly applied test is to determine the presence of micro-organisms in the final flush water is the total count of potable water. The total viable count should not exceed $100 \mathrm{cfu} / \mathrm{ml}$ with the absence of coliforms and E. coli in $100 \mathrm{ml}$ of the flush water (Mettler and Carpentier, 1998). Wirtanen and Salo (2003) suggested use of fluorescent dyes, indirect immune fluorescence, and Quartz microbalance techniques for improving the detection of surface adhered spores in processing plants. The CIP methods with small volumes and low temperatures, such as enzyme-based cleaning and one-phase alkaline cleaning turned out to be the best alternatives for the impact categories like energy use, global warming, acidification, eutrophication and photooxidant formation (Eide et al., 2003). They observed that milk residues flushed out in the rinsing phase were the main contributor to eutrophication and the phosphorus and nitrogen in the detergents also influenced the results. Gentil et al. (2010) investigated the possible contamination of surfaces of food processing lines during CIP procedures and a significant surface contamination has observed based on the spore surface properties. In this study, they succeeded in demonstrating that Bacillus spores from three strains, detached from contaminated surfaces during CIP, were able to contaminate surfaces downstream. They also observed that the most contaminated surfaces during CIP are the areas located after bends and so the cleaning strategy must take into account the re-adhesion phenomenon occurring in disturbed zones. To achieve the most effective CIP results, it is necessary to design the production process and the CIP components and circuits simultaneously, giving equal consideration to production and cleaning requirements (Bremer and Seale, 2010).

\section{Cleaning procedure}

As per the Dairy Practice Council (1993), the following cleaning procedure in a dairy plant is recommended. Pre-mix the required amount of a well-balanced heavy duty alkaline circulation cleaner in a pail with cold water to provide a concentration of 0.7 to 1.0 per cent causticity in the cleaning solution and add the pre-dissolved cleaner directly into the surge tank. Circulate this alkaline cleaning solution for 30 to 45 minutes, maintaining temperature at $175^{\circ} \mathrm{F}$. The standard procedure as explained by Tamime and Robinson (1999) includes the rinsing of the system with clean cold water for 5 to 20 minutes which ensures washing out the remnants of the produced or processed milk, cleaning with an alkaline solution of concentration 1.0-1.5per cent at a temperature $75-80^{\circ} \mathrm{C}$ for 6-45 minutes aimed to remove the deposited organic contaminants like oil, proteins, polysaccharides from the piping surface, rinsing with warm water to wash out alkaline environment, cleaning with an acid agent having a concentration of 0.5-2 per cent for 5-45 minutes at a temperature between $60^{\circ} \mathrm{C}$ and $90^{\circ} \mathrm{C}$ for the elimination of inorganic sediments and final rinsing with cold water for 5 to $20 \mathrm{~min}$.

It is important to specify the correct processing times of cleaning methods, as long standing cleaning process will cause fouling on the surface of processing equipment especially in heat exchanger plate, which result in growth of harmful thermophelic bacteria (Wirtanen and Salo, 2003). Wirtanen and Salo (2003) carried out less environmentally harmful cleaning procedures based on ozonated water and enzyme based agent in CIP and obtained promising results with 1-3 log reduction in spore count by using an ozone concentration of $0.1-0.3$ ppm. Eidie et al. (2003) used four CIP methods for dairies and were compared using life cycle assessment (LCA). The methods were conventional alkaline/acid cleaning with hot water disinfection, one-phase alkaline cleaning with acid chemical disinfection, enzyme based cleaning with acid chemical disinfection and the conventional method with disinfection by cold nitric acid at $\mathrm{pH} 2$.

Cleaning process usually consist of a series of discrete stages including removal of gross debris, pre rinse, detergent circulation, intermediate rinse, second detergent circulation, intermediate rinse disinfection and final rinse (Tamime, 2008).

\section{Conclusion}

Cleaning In Place system in a Dairy Plant consist of the use of various types of detergents, sanitizers or disinfectants for cleaning and these agents can be stored and reused for the cleaning on next day. This system will economize the cleaning procedures in a processing plant, but repeated use may cause the buildup of thermoduric organisms in the pipelines and subsequently in to the pasteurized milk. So timely revision of the cleaning strategies should be carried out to obtain good product quality.

\section{Reference}

[1]. Bremer, P. J. and Seale, R. B. 2010. Clean-in-Place (CIP). Encyclopedia of Industrial Biotechnology: Bioprocess, Bioseparation, and Cell Technology. pp 1-8

[2]. Dairy Practice Council. 1993. Guidelines for cleaning and sanitizing in fluid milk processing plant. Available at http://www.dairypc.org

[3]. Eide, M. H., Homleid, J. P. and mattsson, B. 2003. Life cycle assessment (LCA) of cleaning-in-place processes in dairies. Swiss J. Food Sci and Technol. 36: 303-314

[4]. Genevihe, G., Guiziou il, A., Boyavalb, E. and Daufinc, G. 2002. Nanofiltration for the recovery of caustic cleaning-in-place solutions: robustness towards large variations of composition. Desalination. 49:127-129 
[5]. Gentil, C. L., Sylla, Y. and Faille, C. 2010. Bacterial re-contamination of surfaces of food processing lines during cleaning in place procedures. J. Food Eng. 96: 37-42

[6]. Gentil, C. L., Sylla, Y. and Faille, C. 2010. Bacterial re-contamination of surfaces of food processing lines during cleaning in place procedures. J. Food Eng. 96: 37-42

[7]. Gracia, M and Diaz, M. 2011. Cleaning in place. Comprehensive Biotechnol. 2:983-997

[8]. Jones, M.B., Miller, J.J. and Brown, W.E. 1986. Effectiveness of a quaternary ammonium compound in the presence of hard water and organic soil. Dev. in Ind. Microbiol. 25: 771-777

[9]. Merin, U., Guiziou, G., Boyaval, E. and Daufin, G. 2002. Cleaning-in-place in the dairy industry: criteria for reuse of caustic $(\mathrm{NaOH})$ solutions. Lait. 82:357-366

[10]. Mettler, E. and Carpentier, B. 1998. Variations over time of microbial load and physic- chemical properties of floor materials after cleaning in food industry premises. J. Food prot. 61:57-65

[11]. Mosteller, T. M. and Bishop, J. R. 1993. Sanitizer efficiency against attached bacteria in a milk biofilm. J. Food Prot. 56: 34-41

[12]. Russel, A. and Chopra, I. 1996. Understanding antibacterial action and resistance. ( $2^{\text {nd }}$ ed). Ellis Horwood, London. pp 150-171

[13]. Salo S., Sandholm, M. T. and Wirtanen G. Do we need enhanced low pressure cleaning procedures for open process surfaces? In: Proceedings of $32^{\text {nd }}$ R3 - Nordic Symposium on Contamination Control, $21^{\text {st }}$ December 2001, London. Pp. $185-193$

[14]. Tamime A.Y. and Robinson R.K. 1999. Yoghurt: Science and Technology. Woodhead Publishing Ltd, Cambridge pp 41-156

[15]. Tamime, A.Y. 2008. Cleaning in place- dairy foods and beverage operations. Blackwell Science Ltd, Oxford, pp 2-8

[16]. Troller, J. A. 1993. Sanitation in food processing. Academic press, San Diego. Pp 30-286

[17]. Vlkovai, H., Babakai, V., Seydlova, R., Pavliki, I. and Schlegelovai, J. 2008. Biofilms and hygiene on dairy farms and in the dairy industry, sanitation chemical products and their effectiveness on biofilms a review. Czech J. Food Sci. 26: 309-323

[18]. Walker, S. P., Demirci, A., Graves, R. E., Spencer, S. B. and Roberts, R. F. 2003. CIP cleaning of a pipeline milking system using electrolyzed oxidizing water. ASAE Annual Meeting. Paper number 036181

[19]. Wirtanen G. and Salo S. 2003 Disinfection in food processing, Efficacy testing of disinfectants. Rev. Env. Sci Biotechnol. 2: 293306

[20]. Wirtanen G. and Salo S. 2003 Disinfection in food processing, Efficacy testing of disinfectants. Rev. Env. Sci Biotechnol. 2: 293306 